\title{
Perforating injuries of the eye
}

\author{
ELIZABETH M. EAGLING \\ From the Birmingham and Midland Eye Hospital
}

This review was undertaken to evaluate the outcome of the current management of perforating eye injuries in order to determine reasons for failure to achieve a satisfactory result, and to see where further improvement may be possible.

Since the advent of microsurgical techniques, better wound closure and re-formation of the anterior chamber have led to a greatly improved prognosis for perforating eye injuries (Roper-Hall, 1959). Attention has subsequently been directed towards the management of intraocular damage: the safety of repositing an iris prolapse with an improved visual and cosmetic result has been reported by Callaghan (1956) and by Stein (1958), while immediate aspiration of a damaged lens was recommended (Roper-Hall, I959) to reduce subsequent intraocular inflammation. More recently, Coles and Haik (1972) stressed the importance of performing an extensive anterior vitrectomy in badly injured eyes to limit the development of intraocular fibrosis leading to phthisis and retinal detachment.

In this present study, 228 patients with perforating eye injuries (nine bilateral) have been reviewed; all were admitted to the Birmingham and Midland Eye Hospital between 1971 and 1974. This study does not include patients with small intraocular foreign bodies and a sealed entry wound, as these constitute a different clinical problem.

Since the complications of perforating eye injuries are now determined largely by the extent of intraocular damage, a simple classification on this basis was adopted. Injuries were divided into four groups as follows: Grades I and 2 were injuries confined to the anterior segment; lacerations of the cornea or anterior sclera, with or without uveal prolapse, were classified as Grade I, but if lens damage was also present, they were classified as Grade 2. Injuries involving the posterior segment with vitreous loss were classified as Grade 3, while the more extensive injuries involving both anterior and posterior segmentsthat is, both lens damage and vitreous loss-were classified as Grade 4.

This paper is concerned with the outcome of

Address for reprints: Miss E. M. Eagling, FRCS, Birmingham and Midland Eye Hospital, Birmingham the injuries confined to the anterior segment (Grades $I$ and 2), since the injuries involving the posterior segment have been discussed elsewhere (Eagling, 1975). However, the figures relating to the pattern of injury and the overall visual outcome for the series as a whole are included. The figures given for the visual outcome of Grade 2 injuries differ from those previously reported (Eagling, 1975); this group was reviewed again one year later, since at the time of the first review, surgical treatment of lens damage was incomplete in many patients.

\section{Surgical management}

The surgical repair of these injuries was performed within a few hours of injury in almost all patients, and the following technique was employed: wounds were explored to their full extent; prolapsing uveal tissue was reposited if it was healthy and no infection was present, but if the iris was atonic or badly damaged or the wound was infected, this was abscised. The policy regarding a damaged lens varied: if soft lens matter was present it was washed out, but only in a small percentage of patients was immediate aspiration attempted, or complete extraction performed by an $a b$ externo approach, after primary closure of the laceration. Vitreous presenting in the wound was abscised, and after wound closure with either 8.0 virgin silk sutures or 10.0 monofilament nylon sutures, the anterior chamber (or posterior segment) was reconstituted with air or saline. The follow-up period ranged from six months to five years.

\section{Results}

\section{PATTERN OF INJURY}

The age and sex distributions (Table I) show a similar pattern to those of the previous series (Roper-Hall, I 959; Johnston, I97 I); the commonest injury was a simple laceration to the anterior segment (Grade I), but a significant proportion (25 per cent) had the worst category of injury (Grade 4).

The aetiology of the injuries in this series compared with that of a similar series from this hospital of 17 years ago (Roper-Hall, I959) is presented in Table II. There has been a dramatic increase in the number of perforating eye injuries 
Table I Age and sex incidence, and the spectrum of injury

\begin{tabular}{|c|c|c|c|c|c|}
\hline \multirow{2}{*}{$\begin{array}{l}\text { Age } \\
\text { (years) } \\
0-10\end{array}$} & \multirow{2}{*}{$\begin{array}{l}\text { No. } \\
- \\
59\end{array}$} & \multirow{2}{*}{$\begin{array}{l}\text { Percentage } \\
26\end{array}$} & \multicolumn{3}{|c|}{ Spectrum of injury } \\
\hline & & & Grade & No. & Percentage \\
\hline I I -20 & 62 & 27 & & 一 & \\
\hline $21-30$ & 50 & 22 & I & 97 & $4 I$ \\
\hline $3 I-40$ & 26 & II & 2 & 43 & I 8 \\
\hline $41-50$ & I 5 & 7 & 3 & 37 & I6 \\
\hline $50+$ & 16 & 7 & 4 & 60 & 25 \\
\hline
\end{tabular}

Sex ratio:

Males $=178$, Females $=50-$ male preponderance of $3.5: 1$

Table II Aetiology (including a comparison with the previous series from this hospital)

\begin{tabular}{|c|c|c|c|}
\hline \multirow[b]{2}{*}{ Cause } & \multirow[b]{2}{*}{ No. } & \multicolumn{2}{|c|}{ Percentages } \\
\hline & & I976 & 1959 \\
\hline Road accident & 72 & $3 I$ & 2 \\
\hline Child play & $6 r$ & 26 & 27 \\
\hline Occupational & 36 & 15 & $4 \mathrm{I}$ \\
\hline Domestic & 34 & 14 & 20 \\
\hline Assault, bombs & 19 & 8 & $\mathbf{I}$ \\
\hline Outdoor & 9 & 4 & 6 \\
\hline Sport & 6 & 2 & 3 \\
\hline
\end{tabular}

caused by road accidents and, with the exception of one bomb-blast victim, all the bilateral perforations were from this cause. Conversely, the incidence of occupational injuries has fallen considerably.

\section{OVERALL VISUAL OUTCOME}

Table III gives the visual outcome for each grade of injury, and for the series as a whole: as expected, very few eyes with injuries confined to the anterior segment lost all useful vision, and these were due to established infection from delayed presentation. For injuries involving the posterior segment only (Grade 3), the visual outcome was predominantly good, and those who eventually lost all useful vision did so as a result of late traction retinal detachment. The combined anterior and posterior segment injuries (Grade 4) had the worst outcome, but many of these had no visual potential before repair. The factors contributing to a poor outcome for Grade 3 and 4 injuries, and the suggested management, have been discussed in detail elsewhere (Eagling, 1975).

Only one patient in the whole series developed sympathetic ophthalmitis, representing an incidence of less than 0.5 per cent. The injury in this patient was from a dart, with both lens and posterior segment damage, but the immediate postoperative course was satisfactory with $6 / 12$ vision, and the development of sympathetic ophthalmitis had not been anticipated.

\section{OUTCOME OF ANTERIOR SEGMENT INJURIES \\ Grade I injuries (97 injured eyes)}

This group of patients had corneal or scleral lacerations confined to the anterior segment, without lens damage. Although 94 per cent of patients in this group achieved $6 / 12$ vision or better when corrected, problems arising from corneal scarring and astigmatism detracted from the final outcome.

A vascularized scar was often a complication of an anterior synechia to the wound: 69 patients from this group, who presented with either an iris prolapse or with iris incarceration in the wound, were studied to see if the position of the wound, and the surgical management of the iris prolapse influenced the subsequent incidence of anterior synechiae: the results are presented in Table IV. Both factors were found to affect this: a wound crossing the limbus had a higher incidence of anterior synechiae compared with central wounds:

Table III The overall visual outcome

\begin{tabular}{lllllll}
\hline \multicolumn{7}{c}{ Grades } \\
\cline { 2 - 6 } & I & 2 & 3 & 4 & Total \\
\cline { 2 - 6 } $\begin{array}{l}\text { Good outcome } \\
\text { (percentage) } \\
6 / 6-6 / 12 \text { corrected }\end{array}$ & 94 & $65^{*}$ & 77 & 18 & $68^{*}$ \\
$\begin{array}{l}\text { Bad outcome (percentage) } \\
\text { Inaccurate perception } \\
\text { of light-excised }\end{array}$ & I & 2 & I 7 & 60 & 18 \\
\hline
\end{tabular}

*Figures revised from those reported previously, see text

Table IV The incidence of anterior synechiae in relation to wound position and surgical management of uveal prolapse

\begin{tabular}{|c|c|c|c|c|c|}
\hline \multirow[b]{3}{*}{ Iris } & \multicolumn{5}{|l|}{ Wound } \\
\hline & \multicolumn{2}{|l|}{ Limbal: } & \multicolumn{2}{|l|}{ Central: } & \multirow[b]{2}{*}{ Total } \\
\hline & $\begin{array}{l}\text { Anterior } \\
\text { synechia }\end{array}$ & Nil & $\begin{array}{l}\text { Anterior } \\
\text { synechia }\end{array}$ & Nil & \\
\hline Abscised & 4 & 12 & 0 & 5 & 21 \\
\hline Reposited & 17 & I I & 4 & 16 & 48 \\
\hline Total & - & - & - & - & - \\
\hline
\end{tabular}




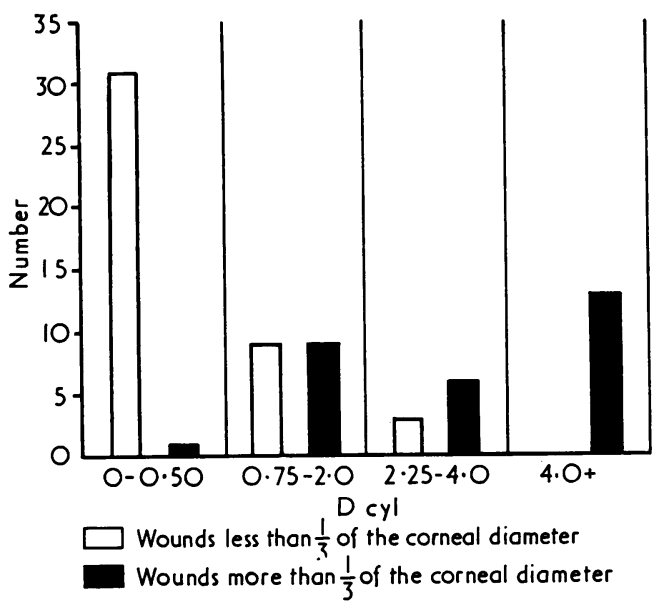

FIG. I Wound astigmatism related to the size of the corneal laceration, Grade I injuries

synechiae occurred more frequently after repositing an iris prolapse as compared with abscision.

Wound astigmatism, requiring either spectacle or contact lens correction, affected half the patients in this group. The principal factor contributing to this was wound size (Fig. I); patients with lacerations involving less than one-third of the corneal diameter had a low incidence of astigmatism and many achieved good vision unaided, while those with lacerations exceeding one-third of the corneal diameter had significant astigmatism requiring correction to achieve good vision; a third of the latter had astigmatism exceeding $4^{\circ} \circ$ dioptres, and in some patients, the error was as high as 10.0 dioptres. However, with the exception of two young children, who had become amblyopic, all these could be corrected to $6 / 12$ vision or better, and corneal grafting was not required.

The 30 patients with lacerations exceeding onethird of the corneal diameter were studied further to see what other factors might be involved: the incidence and degree of astigmatism was no greater for those patients with complete transverse lacerations as compared with those affecting onethird to two-thirds of the corneal diameter. The shape of the laceration was not a significant factor: linear lacerations were present as often as flap or complex lacerations, and astigmatism was associated with axial and peripheral lacerations alike. Of the I 3 patients with astigmatism exceeding $4^{\circ} \circ$ dioptres, only one had a heavily scarred wound from an extensive anterior synechia, while the remainder had fine, fairly regular scars. A study of the axis and power of the astigmatism in six of these patients in whom the wound crossed the visual axis indicated that relative flattening had occurred along the wound and to a lesser extent across the wound; the transverse lacerations had astigmatism requiring high minus cylinders with the axis at $90^{\circ}$ to the wound, while a laceration affecting one radius only had high mixed astigmatism with the axis obliquely related to the wound (Fig. 2).

\section{Grade 2 injuries (43 injured eyes)}

This group consisted of patients with anterior segment injuries involving lens damage who were studied particularly in relation to the functional outcome.

Table $\mathrm{V}$ gives the corrected vision (after a minimum follow-up period of 18 months) in relation to the age of the patient at the time of the injury: there were still four patients requiring further surgery to obtain clear media, and one who had required enucleation after panophthalmitis. With these exceptions, almost all the patients over the age of seven achieved 6/12 vision or better. For this age group, the timing of lens surgery did not affect the ultimate visual acuity; however, in the 8- to 12-year-old group, manifest squints developed rapidly, even in those in whom clear media and contact lens fitting had been achieved within three months of injury. In the older patients successfully fitted with a contact lens, 12 out of 20 patients complained of diplopia, even after a prolonged period of wear, and seven of these have given up

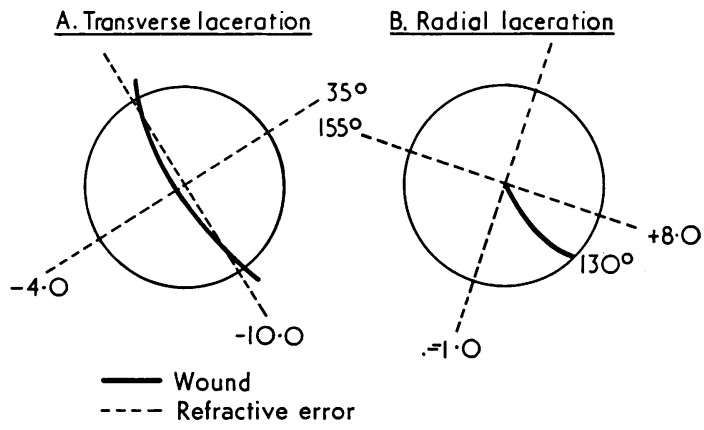

FIG. 2 Examples of astigmatism showing power and axis in relation to the wound

Table V The visual outcome for Grade 2 injuries in relation to age at the time of injury

\begin{tabular}{|c|c|c|c|}
\hline \multirow{2}{*}{ Visual acuity } & \multicolumn{3}{|c|}{ Age (years) } \\
\hline & $<8$ & $8-12$ & $>12$ \\
\hline $6 / 6-6 / 12$ & I & 5 & 22 \\
\hline $6 / 18-6 / 36$ & 4 & $\mathbf{I}$ & 2 \\
\hline 6/6o-perception of light & 3 & I* & $3^{*}$ \\
\hline Excised & 0 & 0 & I \\
\hline
\end{tabular}

*Further surgery required to achieve clear media 
contact lens wear for this reason. The time taken to achieve clear media and contact lens fitting did not influence this. By contrast, four patients with Binkhorst intraocular lenticuli have no problems with diplopia.

The outcome was far less satisfactory for the children under eight years of age: all rapidly developed manifest squints and, with one exception, all have developed dense amblyopia and suppression. Although five of these children had clear media within four months of surgery, treatment by contact lens, Binkhorst intraocular lens or spectacle correction, and occlusion, was not successful in fully reversing this.

\section{Discussion}

When the overall outcome of this series is compared with that of a similar series reported from this hospital 17 years ago (Roper-Hall, 1959), it can be seen that a much higher percentage of patients (68 per cent in $1976 ; 45$ per cent in 1959) are achieving $6 / 12$ vision or better. This largely reflects the better outcome of anterior segment injuries. However, the studies undertaken on this type of injury indicate that there is room for further improvement.

Problems relating to the wound - that is, corneal scarring and vascularization associated with anterior synechiae, and wound astigmatism-were studied in the group of patients without lens damage. Anterior synechiae occurred most frequently after repositing an iris prolapse through a wound encroaching on the limbus; Mackensen (1970) emphasized the importance of repositing an iris prolapse through a separate incision, and ensuring a watertight (as opposed to airtight) wound. As atonicity of the prolapsed iris may allow postoperative contact with the wound peripherally, even if the depth of the anterior chamber is maintained, a peripheral iridectomy through the extremity of a wound encroaching on the limbus is recommended.

Wound astigmatism characterized lacerations exceeding one-third of the corneal diameter: a study of those patients with high degrees of astigmatism suggested that flattening along the wound was responsible for this. Although the process of healing may necessarily cause this to some degree, the very high astigmatic errors must reflect some failure of surgical technique. Flattening of a wound indicates inversion and reflects inadequate suture depth with overtightening; however, in a retrospective study of this nature details such as suture depth were not recorded, and this will require further study on a prospective basis.

Despite these complications related to the wound, the corrected visual outcome for this group was good, and no patient has required corneal grafting.

In the group of patients with anterior segment injuries associated with lens damage, although the corrected vision in those patients of eight or more years was good, the number of patients achieving comfortable vision with contact lens correction was disappointing. The use of intraocular lenticuli may offer a better chance of binocular vision in patients with unilateral aphakia (Girard, Friedman, Moore, Blau, Binkhorst, and Gobin, 1962), and although the numbers treated in this way in this series are small, the results are encouraging.

For the children under eight years, the visual outcome was poor because of amblyopia, despite attempts to reverse this. Even with immediate lens surgery at the time of injury or shortly after, it was difficult to achieve clear media within two months of injury, and by this stage, the amblyopia in young children was very difficult to reverse, even when dealing with the best optical situation with an intraocular lens. The prognosis for this age group in terms of a functional outcome remains poor.

In relation to the question of timing of lens surgery, it was apparent from studying the patients' records that it was not always easy to be certain whether lens damage was present at the time of repair; a layer of fibrin covering the lens capsule in the pupil region may be mistaken for a cataractous lens. If there is doubt, and the posterior segment is not involved, lens surgery can safely be delayed for a few days. In young children, although a damaged lens will spontaneously absorb, early deliberate surgical intervention to achieve clear media as quickly as possible is the only hope of preventing irreversible amblyopia.

Where the extent of damage cannot be visualized because of hyphaema, it is vital to remove this by gentle irrigation with either saline or a fibrinolytic agent, in order to ascertain the extent of the damage. In the absence of involvement of the posterior segment (manifested by vitreous loss), it is less essential to deal with a damaged lens at the time of primary repair, although immediate lens surgery helps to reduce postoperative inflammation; if, however, vitreous loss is present in association with lens damage, it is essential to undertake immediate and radical lens surgery in conjunction with anterior vitrectomy, as the admixture of a damaged lens (especially capsule), vitreous, and blood rapidly leads to anterior segment organization, resulting in phthisis and subsequent retinal detachment (Coles and Haik, 1972; Eagling, 1975).

\section{Conclusions}

This study has shown that although the visual outcome for perforating injuries involving the 
anterior segment has considerably improved during the last 17 years, there remain problems associated with wound scarring and astigmatism, and with traumatic aphakia; for the former, avoidance of anterior synechiae by performing a peripheral iridectomy when repositing an iris prolapse through a wound extending to the limbus, and accurate suturing centred on and transfixing the deepest part of the wound may help to reduce these complications. For the latter, the functional outcome has proved disappointing, particularly in young children; whether the use of intraocular lenticuli can improve on this remains to be seen.

I thank my colleagues at the Birmingham and Midland Eye Hospital for permission to review their patients. I also thank Miss L. Bayliss and Mr R. Carter for technical help.

\section{References}

Callaghan, A. (1956) 'Surgery of Eye Diseases', p. 390. Thomas, Springfield, Ill. COLES, W. H., and HAIK, G. M. (1972) Arch. Ophthal. (Chic.), 87, 621

EAGLING, E. M. (1975) Trans. ophthal. Soc. U.K., 95, 335

GIRARD, L. J., FRIEDMAN, B., MOORE, C. D., BLAU, R. I., BINKHORST, C. D., and GOBIN, M. H. (1962) Arch. Ophthal.

(Chic.), 68, 762

JOHNSTON, s. (1971) Trans. ophthal. Soc. U.K., 91, 895

MACKENSEN, G. (1970) 'Microsurgery of Ocular Injuries', Advances in Ophthalmology, vol. 27, p. I1 5. Karger, Basel ROPER-HALL, M. J. (1959) Trans. ophthal. Soc. U.K., 79, 57

STEIN, R. (1958) Brit. F. Ophthal., 42, 406 